\title{
Aapplication of Correlation diagram method in the oil field
}

\author{
Yaoguang Qi ${ }^{1, a}$, Zhuang Li ${ }^{2, b}$ Fenna Zhang ${ }^{3, c}$ \\ College of mechanical and Electronic Engineering, China University of Petroleum , Qingdao \\ 266580, China;

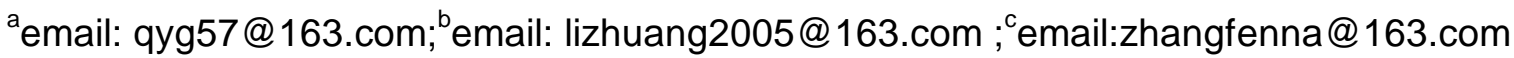

\begin{abstract}
Keywords:carbon fiber continuous sucker rod; overall layout; activity correlation diagram; Operation process

Abstract:The Carbon fiber continuous sucker rod has wide application in oil field, but currenttly it adversely affected by the lack of processes and operations devices. In order to solve these problems by using combination of activity diagram method on the existing vehicle, based on second-class chassis , puts forward the overall design scheme and operation technology of carbon fiber sucker rod equipment. Research shows that this design scheme and technology can satisfy the requirements of HSE oil field,and significantly reduce the labor intensity of workfield operator, improve work efficiency, and provide reference for other devices.
\end{abstract}

\section{Introduction}

The advantages of carbon fiber sucker rods such as high efficiency, low density and no piston effect have been paid more and more attention[1]. But at present, the operation of carbon fiber sucker rod is skid-mounted, that is, before and after the operation by the carrier, crane and other collaborative work, so high operating costs, poor security become urgent problems to be solved[2].

In order to improve the adaptability of oilfield engineering equipment, strength the working efficiency of carbon fiber sucker rod and reduce the operating cost, the possibility of arranging carbon fiber sucker rod working part mount on the second type chassis is studied. Therefore, the technical research of carbon fiber sucker rod vehicle including the overall program design and operational process planning and other key technologies[3].

In this paper, using the activity correlation and relational graph based on the general arrangement principle of carbon fiber sucker rod vehicle, the relationship between the working process, power input and control signal and the close degree matrix of each sub-system, drawn by. Charts, closedly on the key technologies of the general layout were discussed[4].

\section{Principle and Method of Overall Arrangement of Oilfield workover}

\section{Layout principle}

The overall arrangement of the small repair vehicle in the oilfield could satisfy axle load distribution , the number of work equipment, and other factors, so that the operating equipment is rationally distributed to form an organic whole that can meet the operating, running and docking status. The following principles [5]:

(a)The overall layout of the vehicle should satisfy the operation, driving stability, so the layout scheme of the load should be as symmetrical as possible,every bridge shall not be overloaded.

(b) The overall size of the vehicle must meet the national standard, and the layout should be compact, in order to increase the road adaptability, the turning radius the smaller the better.

(c)the placement of each subsystem should be based on the operating process, shorten the power,hydraulic,control and other transmission routes to facilitate the production and manufacture.

(d)The working vehicle should be modular system as the smallest unit, the overall layout should be simple and fresh, easy operation and maintenance.

(e)In order to ensure the safety of operation, drivers should have a broad field of vision. 


\section{Layout method}

Activity correlation diagram method commonly used in the management of production and operation[11]. Considering other conditions (such as the national standard of vehicle, the load of working equipment, the working condition of the equipment, and so on), is arranged according to the close contact arrangement between the subsystems of the working vehicle, and is an advanced management method applied to the layout of the working vehicle system, which comprises the following steps[6,7]:

(a)Analyze and research the composition, function and the close relationship between each subsystem of the operation vehicle, formulate the relationship grade matrix, and analyze other reasons;

(b)Drawing the activity-related graphs;

(c)General arrangement of the working vehicle based on the relation diagram method.

\section{Applications}

This paper take carbon fiber sucker rod vehicle as example, to discuss the scientific method of working vehicle layout based on the activities of the relational diagram

\section{Set Operation Vehicle Target}

Carbon fiber sucker rod vehicle specific technical indexes are as follows: vehicle carbon fiber sucker rod length of $2500 \mathrm{~m}$; with the sucker rod roller rapid replacement requirements; during operation without other auxiliary vehicles; with minor repairs, oil testing and completion function;

According to the composition of the vehicle system and its close relationship, the vehicle can be classified into the following grades,as table 1 following [6-7].

\begin{tabular}{lcc}
\hline Correlation degree & Code & Value \\
\hline Absolute neccessary & $\mathrm{A}$ & 6 \\
Especially important & $\mathrm{E}$ & 5 \\
Important & $\mathrm{I}$ & 4 \\
Ordinary & $\mathrm{O}$ & 3 \\
Unimportant & $\mathrm{U}$ & 2 \\
Not consider & $\mathrm{X}$ & 1 \\
\hline
\end{tabular}

\begin{tabular}{cl}
\hline Code & reason \\
\hline 1 & Process related \\
2 & Dynamic correlation \\
3 & Physical correlation \\
4 & Related control \\
5 & Safety monitoring \\
6 & Other \\
\hline
\end{tabular}

Table 1 The close level table of relationship Table 2 The reason table of close relationship between subsystems between subsystems

carbon fiber continuous sucker rod arrangement is based on the operating process, so it is necessary to put process-related as the primary reason for the relationship, draw the relevant graph, and analyze the degree of relationship, as table 2 following.

\section{Drawing activity-related diagram}

According to its structure and function, the vehicle can divided into following parts: chassis, power ,transmission,sucker rod roller, blowout preventer, cleaning system, hydraulic, control,vehicle the injection head system, taking into account the braking system installed with the drum system, so they were merged, the control part of all subsystems combined to form the vehicle control system and the Division Drilling control room consolidation, the vehicle provider already provided chassis and power system, the operating power source are comes from hydraulic transmission, so the subsystem for the overall layout of the vehicle include: 1 drive system, 2 sucker rod roller system, 3 BOP system, 4 sucker rod cleaning system, 5 hydraulic system, 6 control system, 7 vehicle crane system, 8 injection head system.

The vehicle has two operation states of lifting and lowering the sucker rod and replacing the sucker rod roller. The working process is as follows:

Lifting sucker rod

1) hydraulic outstretched legs to ensure smooth and stable operation vehicle; 
2) lifting injection head, to ensure the continuous sucker rod of carbon fiber is aligned with the center line of the wellhead;

3) connect hydraulic pipeline, injection head lift sucker rod, and sucker rod and roller fixed;

4) rod roller furling all carbon fiber sucker rod, the rest of the heavier rods, plungers and other conventional workover rigs from the conventional manner;

5) disassemble the hydraulic line, hoisting the injection head assembly to the specified position;

6) the hydraulic outrigger is contracted and the work is completed;

Carbon fiber continuous sucker rod lowering process and lifting process are reciprocal process.

Working process for replacing drum of carbon fiber continuous sucker rod working vehicle:

1) hydraulic outrigger out, pumping rod drum hoisting to the designated position;

2) replace the drum to the work cart drum bracket and fix it;

3) hydraulic leg contraction, replacement completed;

Activities related Figure reflects the compactness relationship between any subsystem of the vehicle, in the graph, letter stand for degree of the relationship,numbers explains the reason of the degree between inter-subsystems, by drawing the activity correlation graph,we can see the relationship between the subsystems and the close degree, easy to query and arrange of each subsystem.According to the qualification conditions of carbon fiber continuous sucker rod vehicle, the cause and code of the correlation degree between subsystems are determined, and the activity correlation diagram is drawn as fig1 following:

\begin{tabular}{|l|l|}
\hline Control system & Roller system \\
\hline Blowout prevention system & Cleaning system \\
\hline Hydraulic system & Hydraulic system \\
\hline Injection system & \\
\hline transmission system & \\
\hline
\end{tabular}

Fig.1 all subsystem of activity correlation diagram

4 overall layout using relational graph method.

Relational graph is a trying regular method, relative position according to the close degree of relation in activities related to the rational allocation of each subsystem, subsystem will be a high degree of correlation in the position of vehicle in the layout design in the center, not to consider the size of the system, only as a unit.

The design and optimization of the relationship of "A, E, I, O, U" most of the unit, if the two systems in a number of the same level, the next level is more between subsystems, until all subsystems of the relationship is completely determined.

The subsystems with the most relationships are sequentially arranged next to the central subsystems in order of "A, E, I, O, U", until each sub-system is arranged in the plan view. General arrangement must be related to the degree of tightness as the principle, in order from large to small, until satisfied.

Overall arrangement method:

According to the relative diagram, the system with the largest number of "A" relations is selected according to the activity-related diagram. Based on the working technological process requirements, the vehicle hoisting system is directly connected with other systems. , So the whole car layout around the hoisting system. And then according to the requirements of driller control room, it is arranged in the rear of the Chassis, as the hoisting system requires a larger operating radius and rotation angle, so the same layout in the rear of the vehicle, draw all subsystems relative position diagram is as follows :

5 initial layout of the overall operating vehicle 
The specific area of each subsystem is reflected to the relative position diagram, and then combined with the actual chassis size for the final overall arrangement. Assumed the second-class chassis as rectangle, the vehicle layout shown in Figure 3:

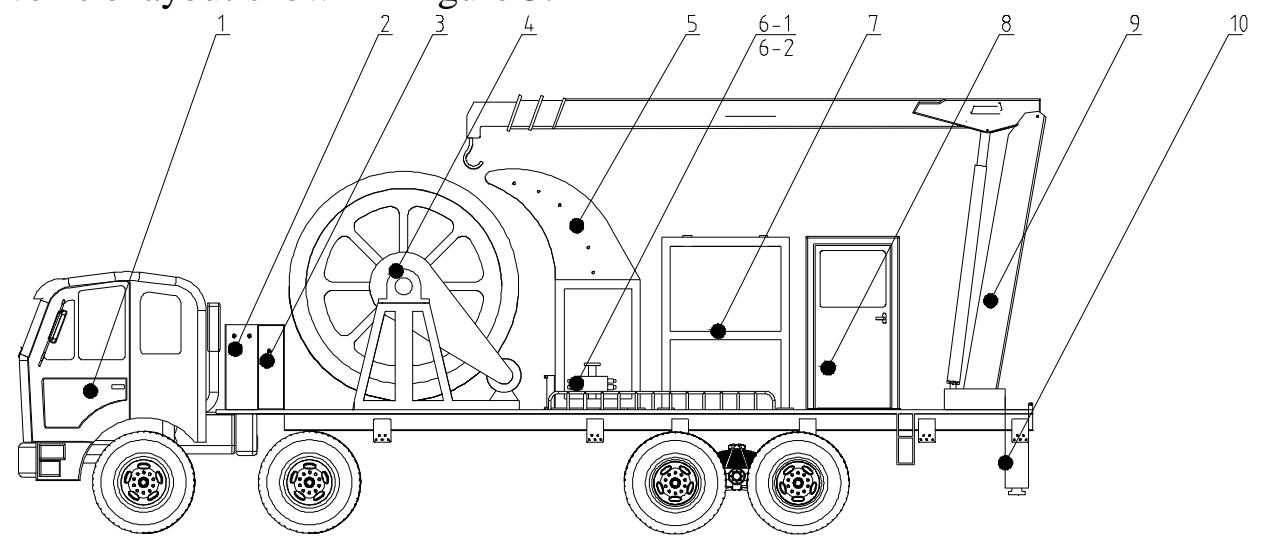

Fig2. Overall layout charm of chassis

1- second-class chassis ; 2- Hydraulic station ; 3- cleaning water box ; 4-roller system ; 5Injection system ; 6-1-Sucker rod preventer ; 6-2-suck rod cleaning device ; 7- frame of Injection ; 8-driller studio ; 9- vehicle-hoist system ; 10- Hydraulic outrigger

\section{Conclusion}

(A)Activity diagram combined with relational graph method considering all factors and constraint relations in the system, it is a scientific management method for overall arrangement of vehicle.

(B)Activity diagram method consider technical conditon, but also from the process of the overall layout of vehicle norms, improve the operation efficiency of vehicle arrangement, convenient the operation of the oilfield workers.

(C)The application of activity-diagram in carbon fiber continuous sucker rod vehicle is based on designer's subjective evaluation, so there are variety of arrangement scheme, the final plan should be combined with the actual situation of the production site, and continuious optimization adjustment.

\section{Acknowledgement}

The research was supported by National Natural Science Foundation of China (Grant No. 51174224) and National Major Project of Oil \& Gas Technology (2011ZX05062-004).

\section{References}

[1] B.X.Sun,The application of activity diagram combined with relationship graph in the oilfield of equipment layout.Petro. Drilling Tech.J.27(6),42-44(1997)

[2] J.L.The research on aircraft layout design technology based on maintenance. Nanjing Aero-Astro Univ.NANJING,(2013)

[3] J.W.Wang,C.S.Wang,S.M.Yang. General layout design of under water production system in Liuhua 4-1 oilfield.Shipbuilding of China.J.52(7),172-178 (2014)

[4] Y.J.Yi,H.L.YANG,Oilfield Workover. China-PIP,BeiJing(2003)

[5] Z.Qin,L.Zhang,J.T.Wang. Research on the design method of hydraulic energy storage and maintenance well machine modeling.Machine Design. 31(8),108-111 (2014)

[6] Y.X.Liu. Research on the general layout design method of the new generation of heavy duty trucks.Jilin Univ.JINLIN(2007)

[7] Y.Z.WANG,X.M.YUAN,R.SUN, Study on the overall design method of 40g-t horizontal centrifugal vibration table[J].Earthquake.Eng.Eng.Vibr .31(6),11-17(2013) 